\title{
Doppler lidar observations of Russian forest fire plumes over Helsinki
}

\section{K E Bozier ${ }^{1}$, G N Pearson ${ }^{2}$ and C G Collier ${ }^{1}$}

\author{
${ }^{1}$ Research Institute of the Built and \\ Human Environment, University of \\ Salford, UK \\ ${ }^{2}$ Halo Photonics, Malvern, UK
}

In August 2006, forest fires in north-western Russia led to elevated concentrations of fine particles reducing air quality in southern Finland over a number of weeks. Predominately easterly and south-easterly winds resulted in smoke plumes extending over the Gulf of Finland and affecting eastern and southern Finland during 7-14 August 2006 and 21-23 August 2006. This article describes observations using Doppler lidar of two episodes where smoke plumes from the Russian forest fires were evident over the Helsinki area on 7 and 9 August 2006. The observations were made during a convective field campaign, part of the Helsinki Testbed, an international mesoscale meteorology research project running from January 2005 until September 2007 (Dabberdt et al., 2005).

During the 2006 fire season, a total of 23046 fires were recorded, affecting 999080 hectares of forested lands and 579234 hectares of non-forested lands with most fires reported in the Kareliya, Leningradskaya and Murmanskaya regions of north-western and western Russia (Global Fire Monitoring Center, 2006). Emissions from boreal fires are important because of their location at climatically sensitive northern latitudes. The main pollutants released during vegetation fires are aerosols, carbon monoxide and dioxide, nitrogen oxides and non-methane hydrocarbons. These emissions play an important role in the atmospheric chemistry and radiative properties of the atmosphere (Damoah et al., 2004). Smoke and aerosol particles scatter sunlight and reflect it directly back to space thereby having a cooling effect on the atmosphere by increasing cloud reflectance (Kaufman and Fraser, 1997). Smoke particles are also a major source of cloud condensation nuclei
(CCN) and increases in CCN affect the microphysics of clouds, thereby altering cloud albedo, affecting the way clouds absorb and reflect sunlight. Emissions from forest fires also have a warming effect on the atmosphere, as greenhouse gases are emitted contributing to the greenhouse effect. Biomass burning is thought to account for as much as $25 \%$ of the total global emission of greenhouse gases (Rebelo, 2006). Changes in the concentration of carbon monoxide and aerosols affect ozone, which plays an important role in the global climate system (Daniel and Solomon, 1998). In 1998, global boreal forest regions experienced some 17.9 million hectares of fire and it has been estimated from models that global fire emissions contribute $8.9 \%$ of total carbon emissions, $13.8 \%$ of carbon monoxide emissions and $12.4 \%$ of methane emissions (Kasischke and Bruhwiler, 2003).

\section{Occurrence of smoke plumes over southern Finland}

During the week commencing 7 August 2006 plumes of smoke from numerous forest fires raging in north-western Russia, close to the Finland/Russia border and to the west of St Petersburg, elevated the concentrations of fine aerosol particles in southern and south-eastern Finland, lowering air quality readings. Winds from the east and south-east advected smoke from the forest fires over southern Finland and on several days the sky became grey, obscuring visibility over large areas of the Greater Helsinki area with a strong acrid smell of smoke being detectable (information courtesy of Helsingin Sanomat, 2006). Figure 1 (a) shows hourly averages of PM2.5 values in and around Helsinki for the period 1200 UTC on 7 August 2006 until 0000 UTC (a)

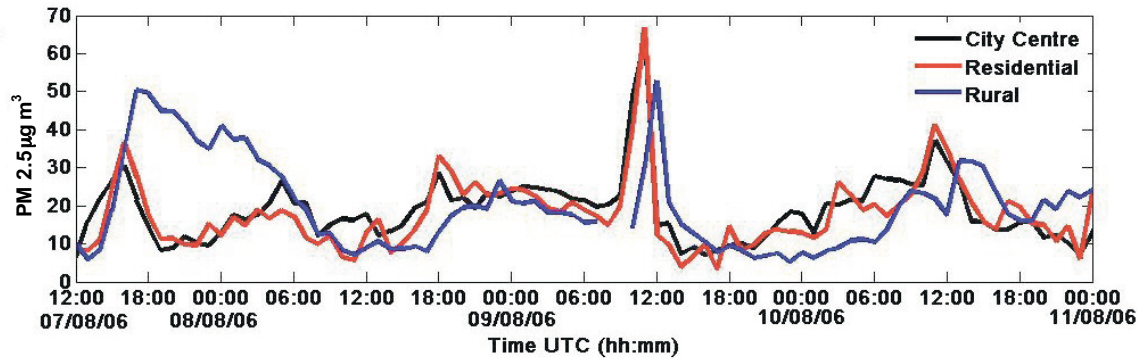

(b)

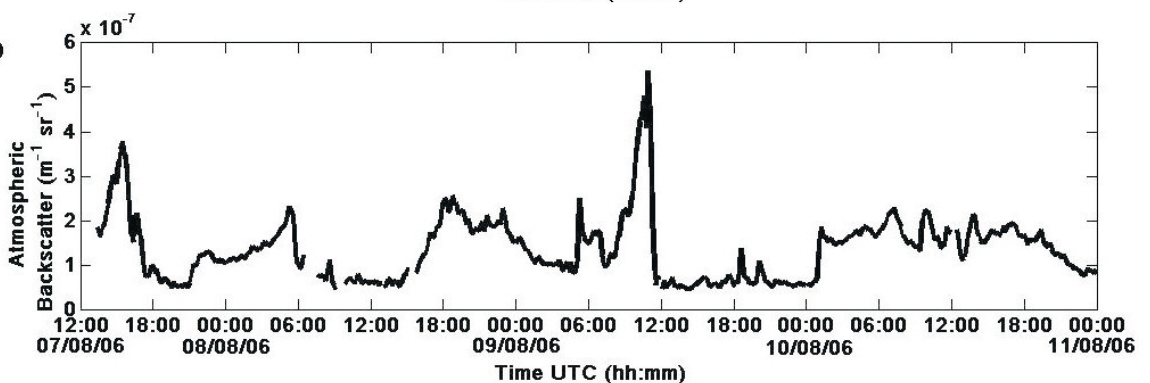

Figure 1. Time series of lidar atmospheric backscatter and PM2.5 measurements taken between 1200 UTC on 7 August 2006 and 0000 UTC on 11 August 2006. Figure 1(a) shows a time series of PM2.5 measurements taken at three air quality stations in the Helsinki area; city centre (black), residential (red) and rural (blue). The time resolution of the air quality data is one hour. The vertical axis shows the PM2.5 concentrations $\left(\mu \mathrm{g} \mathrm{m}^{-3}\right)$ and the horizontal axis is time (UTC). Figure 1(b) shows the lidar time series of ten-minute averaged atmospheric backscatter measurements taken at $45 \mathrm{~m}$ above ground level at Malmi airport. The vertical axis shows atmospheric backscatter $\left(\mathrm{m}^{-1} \mathrm{sr}^{-1}\right)$ and the horizontal axis is time (UTC). 
on 11 August 2006. Data are shown for three air quality monitoring stations; one in the busy city centre district of Helsinki, one in a residential area to the north of Helsinki city centre (urban background) and a rural monitoring station situated to the northwest of Helsinki, which provides air quality readings that are outside of built-up areas of the Metropolitan area (data provided courtesy of Finnish Meteorological Institute). Figure $1(\mathrm{~b})$ shows a time series of the lidar backscatter at a height of $45 \mathrm{~m}$ above ground level for the same time period; these data will be discussed later in the article. The PM2.5 data (Figure 1(a)) show periods where fine particle matter values peaked during the week commencing 7 August 2006. Between 1730UTC on 7 August and 0500UTC on 8 August the rural monitoring station showed higher PM2.5 values than at the city centre and residential monitoring stations. During mid-morning on 9 August 2006, PM2.5 values at all three monitoring stations peaked to between 50 and $70 \mu \mathrm{g} \mathrm{m}^{-3}$. These significantly higher values occurred during the time when visibility was reduced and smoke could be smelt throughout the Helsinki region.

The synoptic chart for 0000UTC on 9 August 2006 is shown in Figure 2 and shows a region of high pressure located to the east of Finland which had been moving slowly to the south-east since 6 August, bringing warm settled weather with light south-easterly winds to southern Finland. Figures 3 and 4 contain ten-minute averaged temperature, humidity, wind speed and direction measurements for the period 0000 UTC on 7 August through to 0900UTC on 8 August 2006 (data courtesy of the Helsinki Testbed Project). Unfortunately the data from the Helsinki Testbed Project automatic weather stations becomes sporadic after 0900UTC on 8 August 2006 and therefore the measurements have not been shown. Data are shown from three weather stations situated in the Helsinki region. The $17 \mathrm{~m}$ measurements are from the rural Malmi airport site, the $80 \mathrm{~m}$ measurements were taken at the Olympic Stadium Tower in downtown Helsinki and the $50 \mathrm{~m}$ and $129 \mathrm{~m}$ measurements were taken in a residential area to the east of the city centre. On 7 August 2006, the wind direction was from the south-east between 0600 and 1800 UTC, with a maximum daily temperature of $25^{\circ} \mathrm{C}$.

The smoke plumes and forest fires close to the Finnish border and to the west of St Petersburg can be seen in the satellite images shown in Figures 5 and 6 . The images were taken with the Moderate Resolution Imaging Spectroradiometer (MODIS) on board the Aqua Earth Observing System (EOS). Plumes of smoke from the forest fires to the west of St Petersburg can be seen advecting towards southern Finland and the

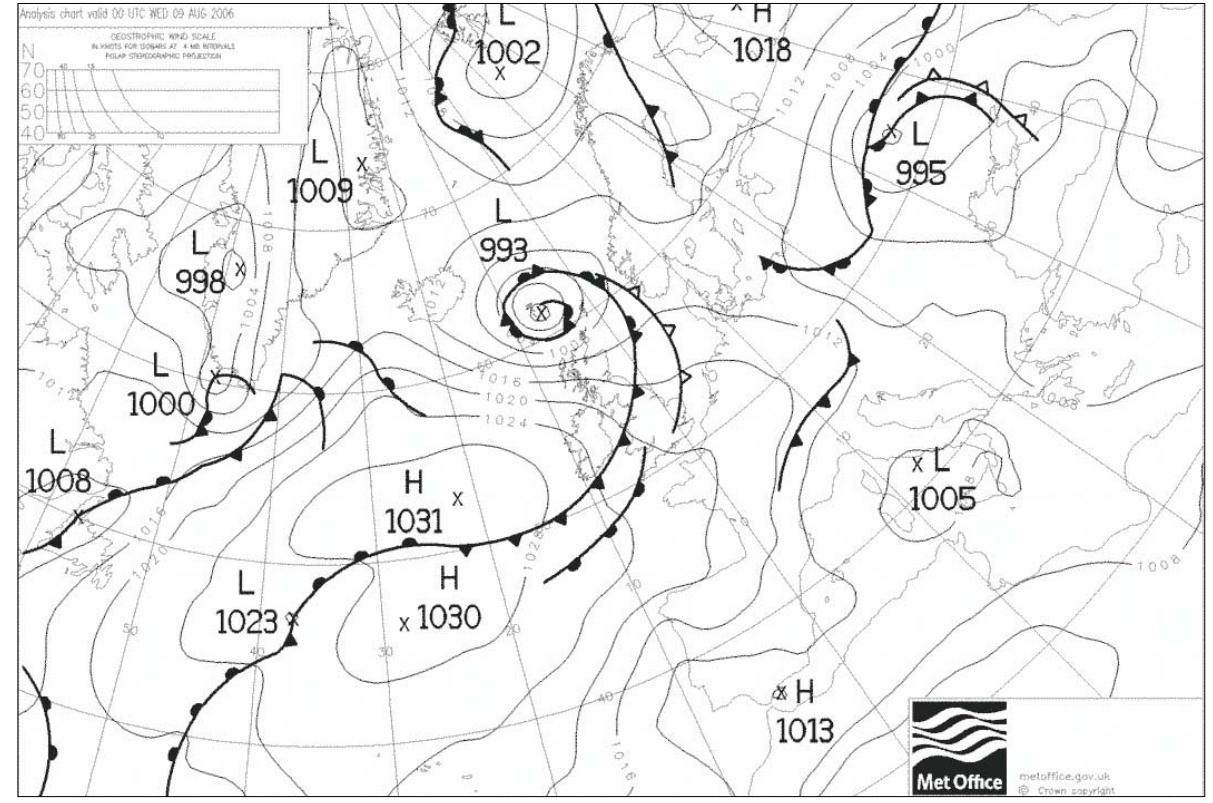

Figure 2. Synoptic chart for 0000 UTC on 9 August 2006. (@ UK Met Office.)
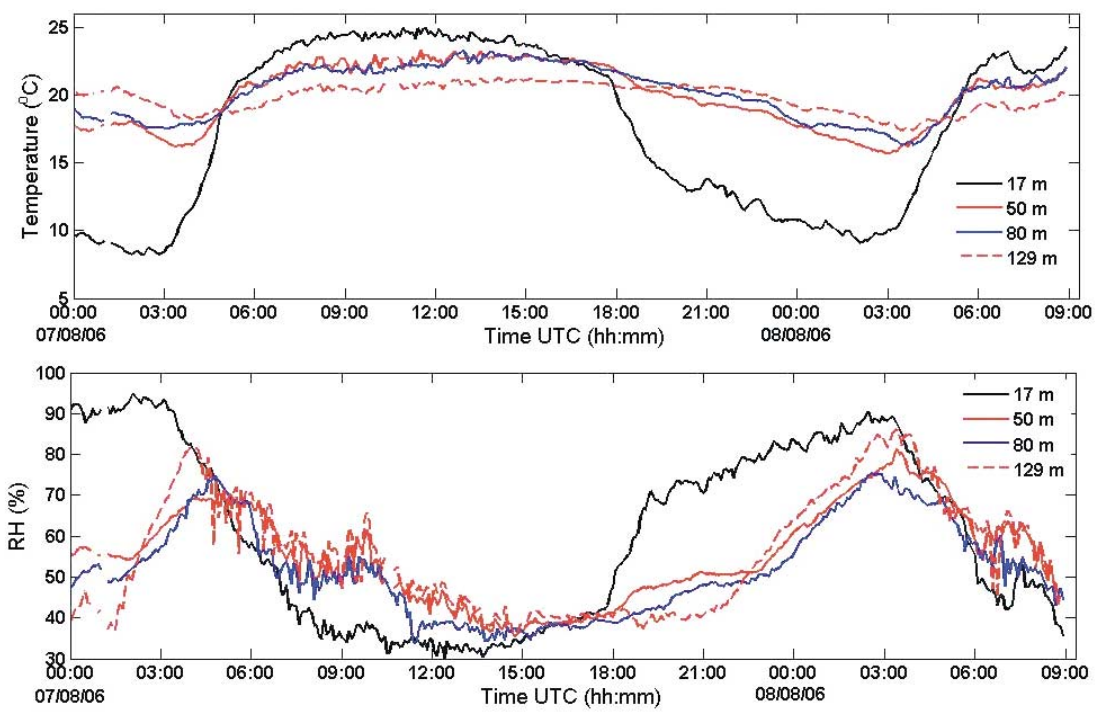

Figure 3. Temperature and relative humidity measurements taken from three automatic weather stations in the Helsinki area. Measurements were taken at $17 \mathrm{~m}$ (black) at the rural Malmi airport weather station site, $80 \mathrm{~m}$ (blue) at the Olympic Stadium Tower weather station site in downtown Helsinki and the $50 \mathrm{~m}$ (red) and $129 \mathrm{~m}$ (red dashed) at the weather station situated in a residential area to the east of Helsinki city centre. (Data are provided courtesy of the Helsinki Testbed Project and were obtained from http://www.testbed.fmi.fi/)

image was taken at 1115 UTC on 7 August 2006. Figure 6 shows a satellite image taken at 1105 UTC on 9 August 2006. Smoke from the forest fires can be seen in the Gulf of Finland reaching the Helsinki area and spreading from Russia towards southern Finland and Sweden. Helsinki has been marked on each satellite image. The red boxes on the satellite image indicate the location of a thermal anomaly that was detected by MODIS using data from the middle infrared and thermal infrared bands, in these cases a fire. The red outlines do not represent the actual size of the fire but indi- cate the perimeter of the $1 \mathrm{~km}$ resolution pixels containing the thermal anomaly detected by MODIS.

\section{Doppler lidar observations of smoke plumes}

A new autonomous Doppler lidar system (Bozier et al., 2006), operated by the University of Salford, participated in the international Helsinki Testbed Project during August and September 2006. The Doppler lidar system was deployed with a view to providing vertical velocity and aerosol 

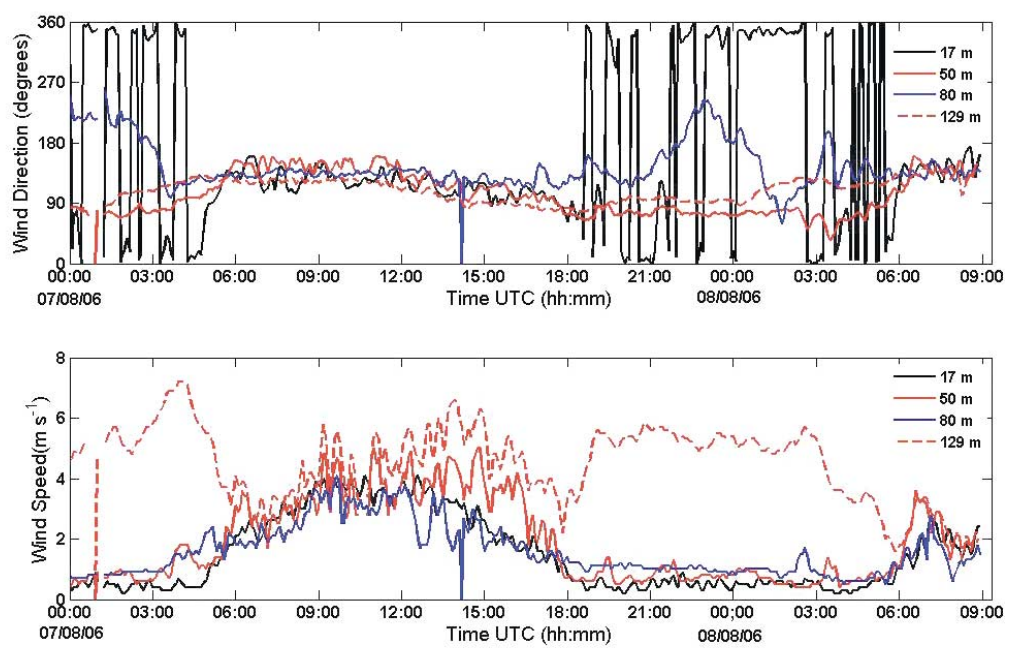

Figure 4. Wind speed and wind direction measurements taken from automatic weather transmitters in the Helsinki area. Measurements were taken at $17 \mathrm{~m}$ (black) at the rural Malmi airport weather station site, $80 \mathrm{~m}$ measurements (blue) at the Olympic Stadium Tower weather station site in downtown Helsinki and the $50 \mathrm{~m}$ (red) and $129 \mathrm{~m}$ (red dashed) at the weather station situated in a residential area to the east of Helsinki city centre. (Data are provided courtesy of the Helsinki Testbed project and were obtained from http://www.testbed. fmi.fi/)

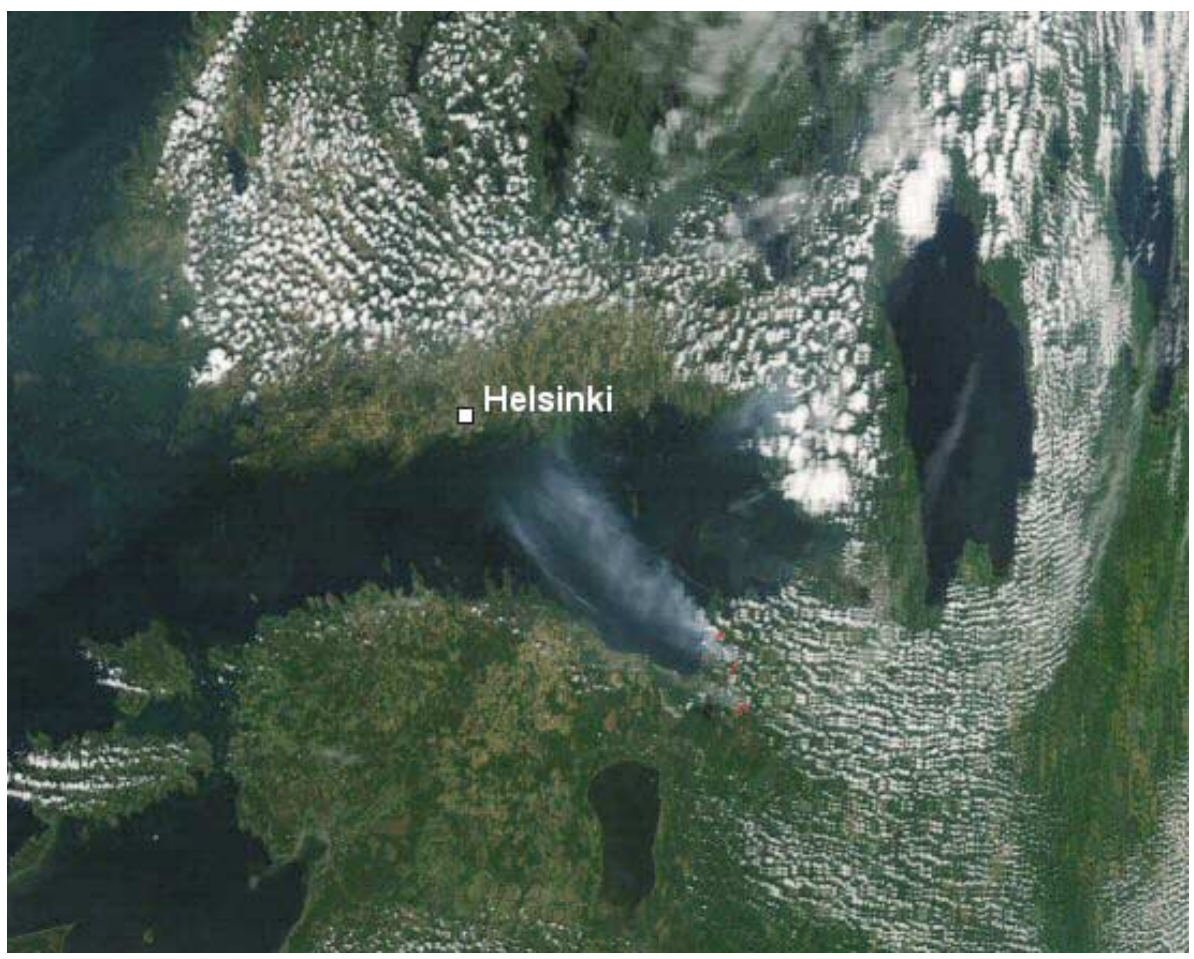

Figure 5. MODIS Aqua satellite image taken at 1115 UTC on 7 August 2006, showing the forest fires (red squares) to the west of St Petersburg. The smoke plume from the forest fires can be seen advecting towards southern Finland. (Image courtesy of MODIS Rapid Response Project at NASA/GSFC obtained from http://rapidfire.sci.gsfc.nasa.gov/)

backscatter profiles within the atmospheric boundary layer during the testbed's convection campaign. The lidar system was sited at Malmi airport, which is located approximately $10 \mathrm{~km}$ to the north-east of Helsinki city centre and $6 \mathrm{~km}$ from the coast. The lidar transmits a short laser pulse and collects the backscattered signal from the illuminated aerosol targets along the path of the laser beam. The primary scatterers are small atmospheric aerosol particles whose

diameters are within an order of magnitude of the lidar wavelength. At optical wavelengths, scattering within the lower atmosphere is primarily by particles with diameters less than $3 \mu \mathrm{m}$, which are sufficiently small to be advected by the wind and serve as an effective tracer of wind velocity.

Accurate estimates of the radial component of the velocity (along the line of sight of the laser beam) are produced as a spatial average over the sensing volume of the transmitted pulse. For the University of Salford Doppler lidar system (which operates at a wavelength of 1.5 microns in the near infrared) this sensing volume is a narrow, pencil-shaped volume approximately $10 \mathrm{~cm}$ in diameter (transverse to the beam direction) and $35 \mathrm{~m}$ long. To improve the accuracy of the measurements the signals from 30000 lidar pulses were averaged. The maximum range of the lidar system was set to $1200 \mathrm{~m}$ and the data were processed using a $30 \mathrm{~m}$ range gate. These settings provided 40 radial velocity and atmospheric backscatter measurements along the line of sight of the lidar beam every 3 seconds. Profiling vertical velocities and convective fluxes close to the ground requires a short minimum range and the capability to measure $\pm 3 \mathrm{~m} \mathrm{~s}^{-1}$ velocities with high accuracy, temporal and spatial resolutions. This new remote sensing instrument has a minimum range of $30 \mathrm{~m}$ and can yield velocity measurement errors of $<0.1 \mathrm{~m} \mathrm{~s}^{-1}$ for averaging times of the order seconds. It is therefore very well suited to studying convection in the boundary layer.

The lidar system was set with a fixed vertical beam and measurements were started at 0930 UTC on 7 August 2006. High backscatter returns were apparent in the lidar data from 1320UTC on 7 August 2006 and were seen throughout the data during the next several days. The high backscatter not only occurred close to ground level, but also as elevated layers within the atmospheric boundary layer. The lidar backscatter time series shown in Figure 1(b) was taken at a height of $45 \mathrm{~m}$ above ground level. The peaks seen in the lidar time series correspond with the elevated concentrations seen in the PM2.5 measurement shown in Figure 1(a). There is a short time lag between the lidar and PM2.5 measurements, which is due to the lidar system being situated further to the east of the residential and rural air quality monitoring stations. From the satellite images shown in Figures 5 and 6 we can surmise that the high backscatter seen in the lidar data is due to smoke particulates and aerosol from the forest fires in Russia. The redistribution of the forest fire smoke plume within the atmospheric boundary layer by convective activity is illustrated using two data sets taken on 7 and 9 August 2006.

\section{August 2006}

During the week commencing 7 August 2006 the Doppler velocity and atmospheric backscatter data show a daily cycle of strong convective activity building from midmorning and then decaying in the evening leading to a stable boundary layer persisting through the night. An 11-hour time series of atmospheric backscatter measurements 


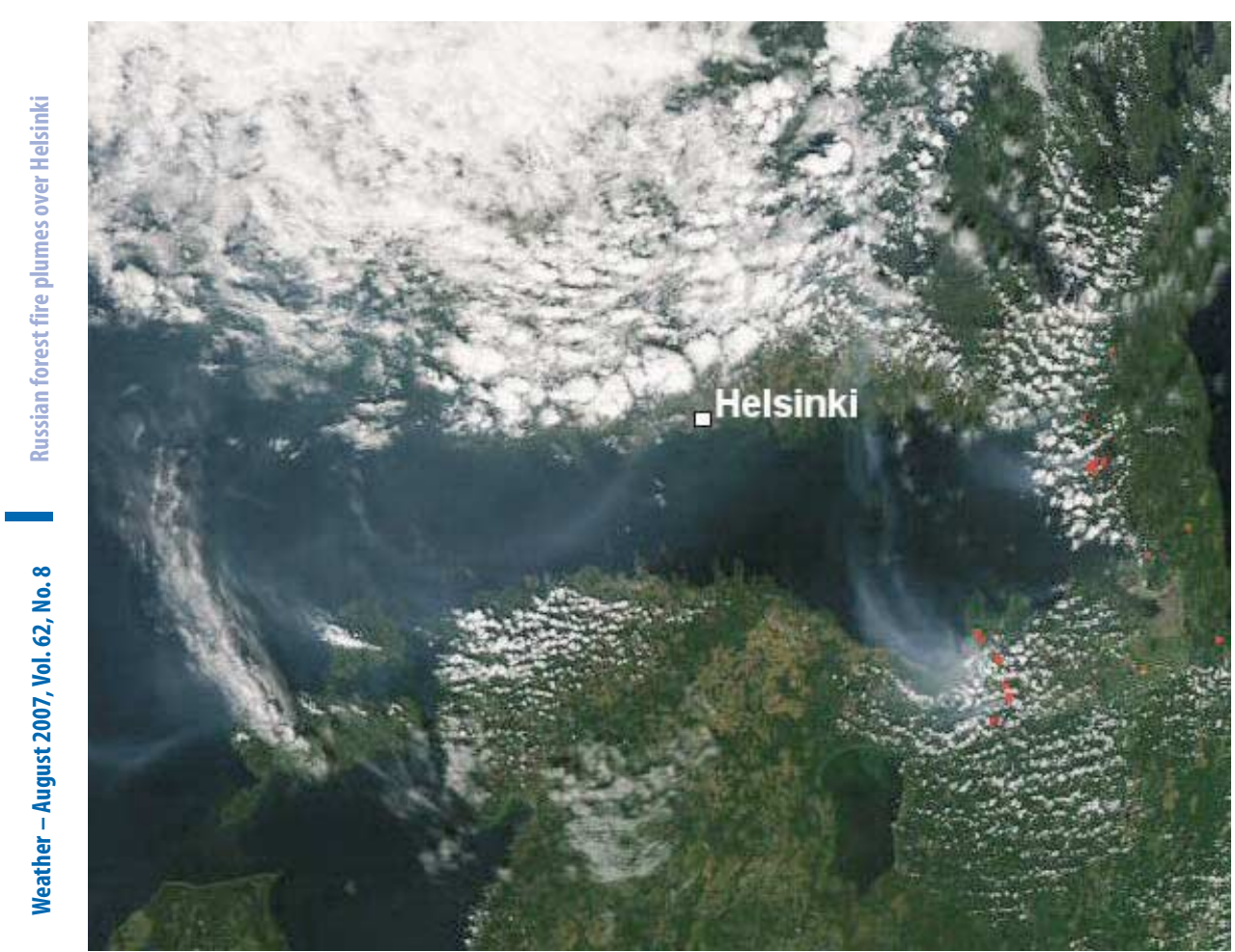

Figure 6. MODIS Aqua satellite image taken at 1105 UTC on 9 August 2006, showing the forest fires (red squares) to the west of St Petersburg and close to the Finnish border. Smoke from the forest fires can be seen covering the Gulf of Finland and southern Finland. (Image courtesy of MODIS Rapid Response Project at NASA/GSFC obtained from http://rapidfire.sci.gsfc.nasa.gov/)

taken between 1300 and 2359 UTC on 7 August are shown in Figure 7. Time is shown on the horizontal axis and height above ground level on the vertical axis. The yellow-red colours on the plot in Figure 7 indicate where the greatest atmospheric backscatter occurs with less backscatter indicated by the blue colours. Black areas on the plot indicate where the backscattered signal fell below the noise level of the lidar system and these data have been removed. The ability of the lidar system to provide measurements is dependent on the amount of particulates in the atmosphere. Generally, particulates are contained within the boundary layer and the air above is usually cleaner; the decrease in the backscattered lidar signal is one way of determining the depth of the atmospheric boundary layer (Cohn and Angevine, 2000).
An increase in the atmospheric backscatter occurs at approximately 1400 UTC in Figure 7 and the signal is strongest between 700 and $900 \mathrm{~m}$ indicating that there is a higher layer of backscatter present at this level; this layer persists until 2100UTC. The atmospheric backscatter from near ground level up to the top of the atmospheric boundary layer increases and decreases throughout the time period with the backscatter highest between 1500 and 1600 UTC. At approximately 1700 UTC the signal starts to decay in the lowest $200 \mathrm{~m}$ with the signal becoming weaker until 1900 UTC when the lidar is not capable of providing measurements above $400 \mathrm{~m}$, due to lack of signal. Measurements from the automatic weather station situated at Malmi airport, co-located with the lidar system, show that this decay in the atmospheric

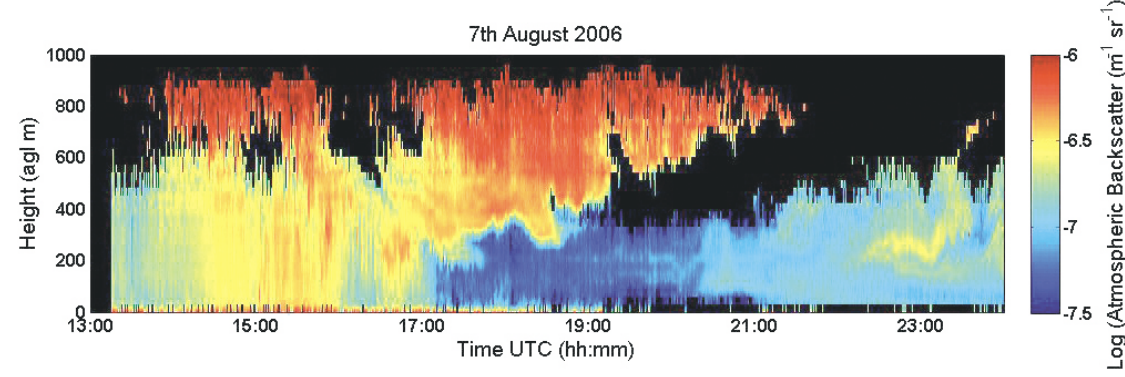

Figure 7. Time series of lidar atmospheric backscatter measurements taken on 7 August 2006, 1300-2359 UTC. The log of the atmospheric backscatter is shown. The vertical axis shows height above ground level (m) and the 206 horizontal axis is time (UTC). backscatter signal corresponds to a decrease in temperature and wind speed, an increase in the relative humidity along with a change in wind direction from southeasterly to northerly (Figures 3 and 4). The changes in temperature, relative humidity and wind direction indicate cleaner air from the north of Finland replacing the dirty south-easterly air flow from Russia.

Figure 8 shows a 20-minute time series of data acquired on 7 August 2006 between 1400 and 1420 UTC (1700 and $1720 \mathrm{~h}$ local time). Figure 8 (a) shows the log of the atmospheric backscatter with the corresponding vertical velocities recorded during the 20-minute time period shown in Figure 8(b). For both images in Figure 8, the vertical axis shows height above ground level and the horizontal axis shows the 20-minute time period. The black areas on the plots indicate where the backscattered signal fell below the noise level of the lidar system and these data have been removed. From examining the fall-off in backscatter signal the depth of the atmospheric boundary layer can be estimated. The time series in Figure 8(a) shows the amount of backscatter within the atmospheric boundary layer which has a depth of approximately $650 \mathrm{~m}$ between 1400 and 1420 UTC. An anomalously high backscatter layer can be seen above the boundary layer between 650 and $1000 \mathrm{~m}$. The backscatter signal at this height is not large enough to indicate cloud, and is attributed to a smoke plume advected from the Russian forest fires. The corresponding vertical velocity measurements are shown in Figure $8(\mathrm{~b})$, where negative, green-blue coloured velocities indicate downward motion and positive, yellow-red coloured velocities indicate upward motion, showing where convective cells occur in the vertical velocity data.

By comparing the vertical velocity data with the backscatter data the vertical motion due to the convective cells can be seen to be correlated with the undulations that can be seen at the bottom of the elevated smoke plume. Downward entrainment of the smoke plume into the lower boundary layer occurs with the downdraughts. The most prominent downdraught occurs at 1417 UTC and the smoke plume can be seen to extend several hundred metres down into the cleaner air within the atmospheric boundary layer. From the measurements shown in Figures 3 and 4 the mean wind speed at Malmi airport between 1400 and 1420 UTC was $3.1 \mathrm{~m} \mathrm{~s}^{-1}$ with air flow from the south-east.

\section{August 2006}

Figure 9 shows a 20-minute time series of data acquired on 9 August 2006 between 1040 and 1100 UTC (1340 and $1400 \mathrm{~h}$ local time). The plot in Figure 9(a) shows the log 

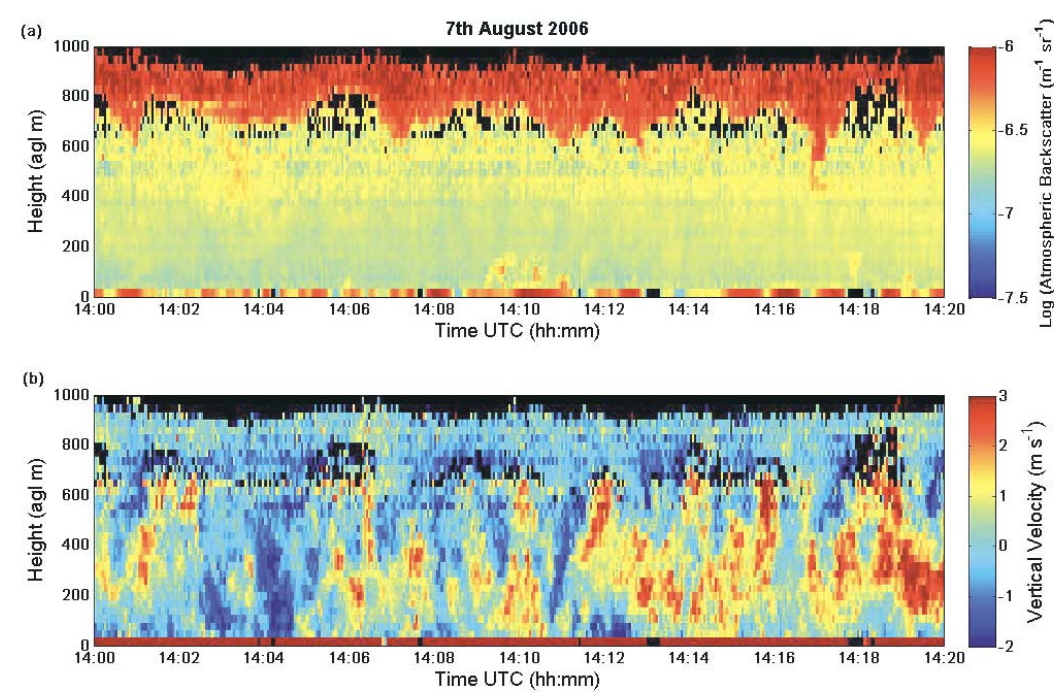

Figure 8. Time series of lidar atmospheric backscatter and vertical velocity measurements taken on 7 August 2006, 1400-1420 UTC. The log of the atmospheric backscatter is shown in Figure 8(a) with the vertical velocity data from the lidar shown in Figure $8(b)$. The vertical axis shows height above ground level $(m)$ and the horizontal axis is time (UTC).
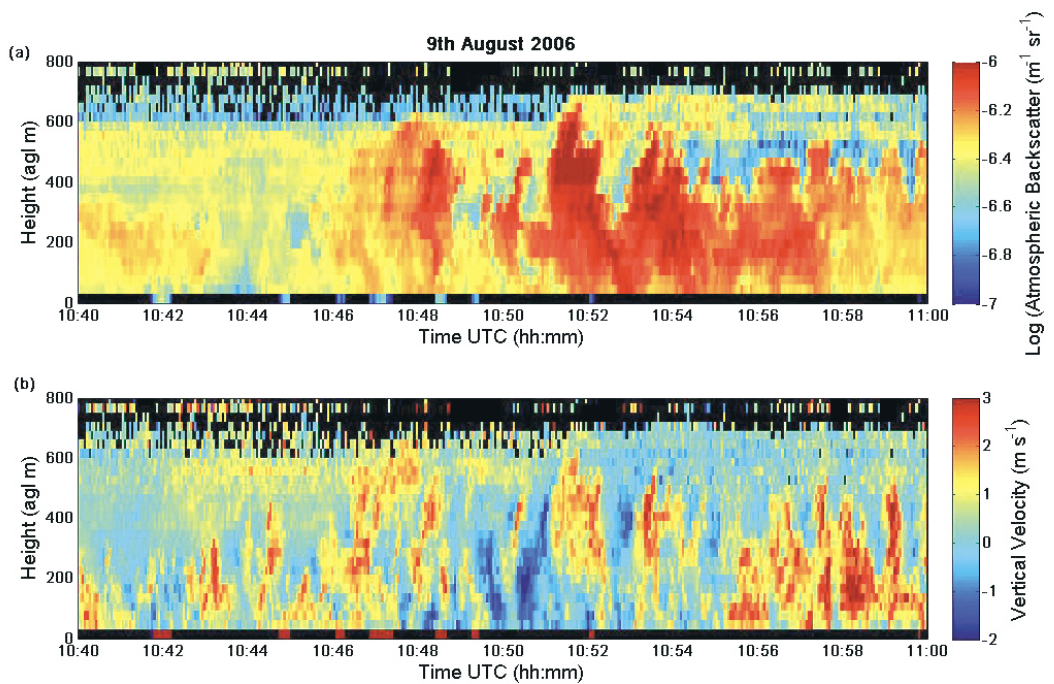

Figure 9. Time series of lidar atmospheric backscatter and vertical velocity measurements taken on 9 August 2006, 1040-1100 UTC. The log of the atmospheric backscatter is shown in Figure 9(a) with the vertical velocity data from the lidar shown in Figure $9(b)$. The vertical axis shows height above ground level $(\mathrm{m})$ and the horizontal axis is time (UTC).

of the atmospheric backscatter with the plot in Figure 9 (b) showing the vertical velocities recorded during the 20-minute time period. The axes and vertical velocity properties are the same as those described for Figure 8. From examining data for the 24-hour time series of lidar measurements (not shown), it can be seen that the growth of the atmospheric boundary layer by convection started around 0640 UTC (0940 h local time) on 9 August 2006. The data shown in Figure 9 indicate that the depth of the boundary layer, at the start of the time series, is approximately $600 \mathrm{~m}$. From 1046 UTC the
From approximately 1100 until $1430 \mathrm{~h}$ local time a smoke smell was readily perceived by local residents and the authors of this article within the Helsinki area. Visibility was also notably reduced due to the haze caused by the smoke plume. The lidar atmospheric backscatter data show a gradual increase in intensity throughout the morning of 9 August 2006 starting around 0815 UTC ( $1115 \mathrm{~h}$ local time). The lidar measurements correspond with the air quality data shown in Figure 1(a). The rural air quality monitoring station has a time lag compared to the downtown and residential stations in Helsinki. Air moving from the south-east would reach the air quality stations in Helsinki before reaching the rural station situated $20 \mathrm{~km}$ to the north-west. The atmospheric backscatter starts to decrease after 1100 UTC ( $1400 \mathrm{~h}$ local time) and then falls below the earlier morning level within a short time period. The increase in the lidar backscatter correlates with the haze and smoke plume observed within the Greater Helsinki area and the measurements from the air quality stations. The satellite image in Figure 6 shows the smoke plume spreading from Russia into the Gulf of Finland and over southern Finland, towards the Helsinki area. A Swedish newspaper reported that on this day residents in Stockholm were able to smell smoke due to the Russian forest fires, $700 \mathrm{~km}$ away (information courtesy of The Local, 2006).

\section{Conclusions}

Forest fire plumes can cause air quality to be perturbed over large areas. Macroscopic transport by the ambient wind field can be monitored from space and networks of ground-based sensors. However, details of the layering and vertical exchange within the boundary layer cannot be readily studied with such sensors. Autonomous pulsed Doppler lidar instruments offer a remote sensing technology which is well suited to monitoring these processes. Such an instrument was deployed at the Helsinki Testbed during August and September 2006 where it operated continuously for eight weeks.

The time series of lidar backscatter and vertical velocity data presented here show two interesting cases of vertical transport of aerosol within the atmospheric boundary layer. In addition to the lidar data, air quality and automatic weather station measurements along with satellite images have been used to illustrate the transport of smoke plumes from Russian forest fires over southern Finland. On 7 August, the lidar data show aerosol from an elevated plume layer entrained by downdraughts into the cleaner boundary layer below. On 9 August 2006, the lidar data show how convective 
cells inject aerosol from a lower layer into the cleaner air above during the development of the boundary layer in the early afternoon (local time). The correlation of the atmospheric backscatter data with the vertical velocity data highlights the role of convection in the exchange and redistribution of aerosol between different atmospheric layers in the lower atmosphere.

Monitoring of such events is an important factor in determining the distribution of aerosol layers and air quality within the boundary layer. The new Salford autonomous Doppler lidar system will provide detailed high temporal and spatial resolution measurements of boundary layer structure and will be used to provide longterm monitoring of the atmospheric boundary layer.

\section{Acknowledgements}

The authors wish to thank the Finnish Meteorological Institute and Vaisala Oyj for their help with the installation of the lidar system at Malmi airport, Helsinki, and for access to the air quality data.

\section{References}

Bozier KE, Davies F, Collier CG. 2006. Autonomous Doppler lidar system for atmospheric boundary layer monitoring Proceedings of Photon 06, Manchester, UK, 4-7 September 2006.

Cohn SA, Angevine WM. 2000. Boundary layer height and entrainment zone thickness measured by lidars and windprofiling radars. J. Appl. Meteorol. 39:

1233-1247.

Dabberdt W, Koistinen J, Poutiainen J, Saltikoff E, Turtiainen H. 2005. The Helsinki Mesoscale Testbed. An invitation to use a new 3-D observation network. Bull. Am. Met. Soc. 86: 906-907.

Damoah R, Spichtinger N, Forster C, James $P$, Mattis I, Wandinger U, Beirle S, Wagner T, Stohl A. 2004. Around the world in 17 days - hemispheric-scale transport of forest fire smoke from Russia in May 2003. Atmos. Chem. Phys. 4: 1311-1321.

Daniel JS, Soloman S. 1998. On the climate forcing of carbon monoxide, J. Geophys. Res. 103: 13249-13260.

Global Fire Monitoring Center. 2006.

Global Fire Monitoring Center (GFMC)/Fire Ecology Research Group. http://www.fire. uni-freiburg.de/

Helsingin Sanomat. 2006. Online Finnish newspaper - international edition. http:// www.hs.fi/english/article/1135220974153/
Kasischke ES, Bruhwiler LP. 2003.

Emissions of carbon dioxide, carbon monoxide and methane from boreal forest fires in 1998. J. Geophys. Res. 108: FFR 2-1 to 2-14.

Kaufman Y, Fraser R. 1997. The effect of smoke particles on clouds and climate forcing. Science 277: 1636-1432.

Rebelo LM. 2006. An investigation into the emissions of biomass burning, and their monitoring by remote sensing. http://www.geog.ucl.ac.uk/ /rebelo/gcm essay.html

The Local. 2006. Online Swedish newspaper. http://www.thelocal.se/ article.php?|D=4559\&date $=20060809$

Correspondence to: Professor Chris Collier, Research Institute of the Built and Human Environment,

School of Environment and Life Sciences, Peel Building,

University of Salford,

Salford,

M5 4WT.

Email: c.g.collier@salford.ac.uk

(c) Royal Meteorological Society, 2007

DOI: 10.1002/wea.48

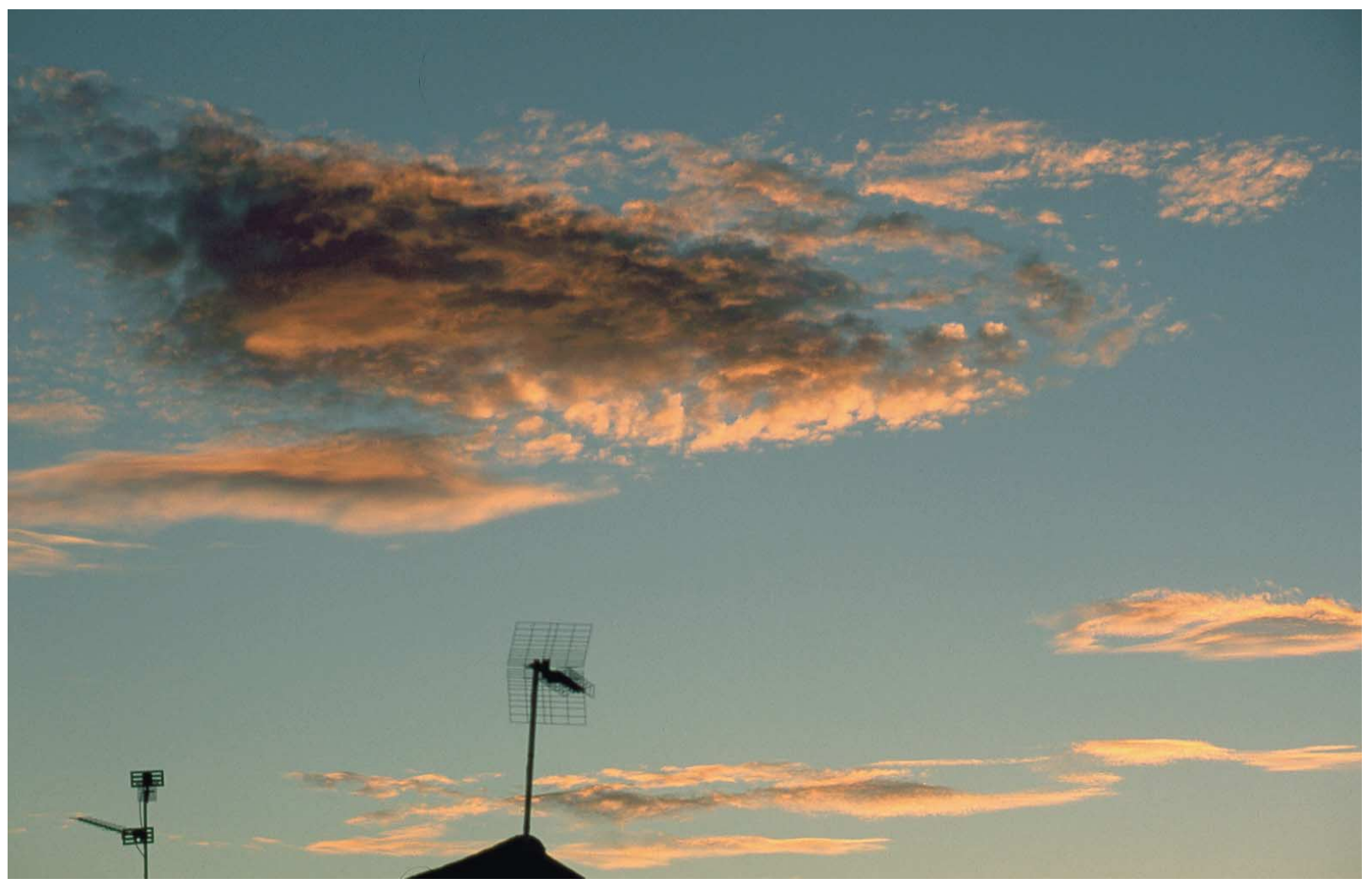

Patches of altocumulus illuminated at sunset, Wokingham, Berkshire, 1858 BST on 26 September 2004. (๑ George D. Anderson.) 